\title{
INSOMNIA AND HYPNOTIC USE IN CAMPO GRANDE GENERAL POPULATION, BRAZIL
}

\author{
José Carlos Souza', Luiz Alberto Magna², Rubens Reimão ${ }^{3}$
}

\begin{abstract}
The insomnia prevalence in general population was determined by means of 408 home interviews of adults, in a representative sample of Campo Grande city, Brazil. The random sample was stratified by sex, age and economic social status. Insomnia subtypes evaluated were the disorders of sleep initiation (DSI), sleep maintenance (DSM) and early awakening (DEA). A structured questionnaire was used with the consent from the interviewed subjects. Statistics used chi-square, and Fisher tests; and inferences based on binomial distribution parameters; the significance level was $5 \%$ and confidence interval $(\mathrm{Cl})$ was $95 \%$.The general prevalence of insomnia was $19.1 \%(s d=2.0 \%)$, mostly women $(p=0.0015)$, and people of less years of schooling $(p=0.0317)$, subtype DSI $(14.2 \%, p=0.0043)$, and chronic $(p=0.7022)$. Hypnotic drugs were used by $6.9 \%(s d=1.3 \%)$ in the last month. Use in the last 2 years, $70.3 \%$ mostly insomniacs $(p<0.0001)$, women $(p=0.0372)$ and people over 30 years of age $(p=0.0536)$.
\end{abstract}

KEY WORDS: sleep, sleep disorders, insomnia, hypnotic use, general population.

Insônia e uso de hipnóticos na população geral de Campo Grande, MS

RESUMO - A prevalência de insônia foi determinada por meio de 408 entrevistas domiciliares de adultos, em amostra representativa da população geral da cidade de Campo Grande, MS. A amostragem aleatória foi estratificada por sexo, idade e classe social. Os subtipos de insônia avaliados foram os distúrbios de iniciar o sono (DIS), de manutenção do sono e de despertar final precoce. Foi utilizado questionário estruturado com consentimento dos entrevistados. Usaram-se os testes de qui-quadrado e Fisher e inferências com base nos parâmetros da distribuição binomial; nível de significância $5 \%$ e intervalo de confiança (IC) $95 \%$. A prevalência geral de insônia foi $19,1 \%(s d=2,0 \%)$, principalmente mulheres $(0,0015)$ e pessoas com menor nível educacional $(p=0,0317)$, subtipo DSI $(14,2 \%, p=0,0043)$ e crônica $(p=0,7022)$. Drogas hipnóticas foram usadas em $6,9 \%(s d=1,3 \%)$ no último mês. 0 uso nos últimos 2 anos foi em $70,3 \%$, principalmente insones $(p<0,0001)$, mulheres $(p=0,0372)$ e pessoas acima de 30 de idade $(p=0,0536)$.

PALAVRAS-CHAVE: sono, distúrbios do sono, insônia, hipnótico, população geral.

Insomnia and the use of hypnotic drugs are very common in general population ${ }^{1-6}$. In the last decade there was an increase in population surveys in the urban and rural regions ${ }^{2,3,7-10}$. Insomnia is a symptom that requires expensive specialized treatments, serious consequences to the public health, to the productivity, and to the quality of life $\mathrm{e}^{1,5,6,11,12}$.

The objective of this study is to detect the general prevalence of insomnia in the Campo Grande city general population, to detect insomnia sub types, and the use of hypnotic drugs in general population, and to have the independent variables compared.

The present survey is part of a larger project we are engaged to determine sleep habits and sleep disorders in this city.

\section{METHOD}

408 inhabitants of 18 years old or over were interviewed in the period from April $3^{\text {rd }}$ to $8^{\text {th }}, 2001$ in 7 urban regions in the city of Campo Grande, State of Mato Grosso do Sul, Brazil. The randomized sampling was obtained through the cluster method and was stratified with quotas of sex and age (according to Instituto Brasileiro de Geografia e Estatística, 1996) ${ }^{13}$, and stratified by economic social status based on Brazilian Market Research Association ${ }^{14}$.

Initially a pilot study was done with 30 people, to adjust the questionnaire to the region of study, as well as to ade-

From the Campinas State University, Campinas, Campinas SP, Brazil; and the Clinical Neurology Division, Hospital das Clinicas, University of Sao Paulo Medical School São Paulo SP, Brazil: 'Psychiatrist; Professor, Dom Bosco Catholic University, Campo Grande; Mental Health Post-Graduate Course, Campinas State University. ${ }^{2}$ Head, Medical Genetics Department, Campinas State University. ${ }^{3}$ Assistant, M.D., Ph.D., Division of Clinical Neurology. This research was partially funded by Dom Bosco Catholic University, Campo Grande, MS, and Produtos Roche Químicos e Farmacêuticos S/A, Sao Paulo, SP.

Received 5 March 2002, received in final form 10 May 2002. Accepted 22 May 2002.

Dr. Rubens Reimão - Avenida Indianópolis 2784 - 04062-003 São Paulo SP - Brasil. FAX 1155897422. 
quate staff of researchers to the instrument. For the field research, the cluster system was used, allotting successive suburbs and blocks where the home personal interviews were done. The 408 home personal interviews were carried out by a staff of field research properly trained by the authors, and a consistent application of the questionnaire was obtained.

A standard individual questionnaire was used adapted from Giglio $^{15}$ and the American Sleep Disorders Association $(\mathrm{ASDA})^{16}$, with the following independent variables: sex, age, years of schooling, economic social status, marital status, and occupation of the interviewed. The years of schooling groups were: 0 to 4 years; 5 to 8 years; 9 to 12 years; college/ partial; college/complete.

For the definition of the insomnia the $\mathrm{ASDA}^{16}$ criteria were applied according to the presence of the following: a) any complaint of insomnia in the last month; b) of any difficulty of over thirty minutes to get to sleep or Disorders of Sleep Initiation (DSI) or initial insomnia; c) of waking up during the night for more than two times for 30 minutes or more, after have fallen asleep, or of Disorder of Sleep Maintenance (DSM) or intermediary insomnia; d) of waking up earlier than wished or of Disorders of Early Arousing (DEA) or terminal insomnia; with a frequency of at least three times a week followed by any degree of uneasiness or early negative effects concerning the next day activities performance (slight, light insomnia, moderate insomnia, intense, severe insomnia). Insomnia is classified according to its duration as being acute up to one month or chronic when over one month.

The instrument evaluated DSI, DSM, DEA in the frequency of 3 or more times a week, in a month prior to the interview (acute insomnia) and over a month (chronic insomnia), with some degree of uneasiness and impairment concerning the activities the following day (slight, moderate, and intense). It also evaluated the use of hypnotic drugs in the prior month and throughout the life span, in the frequency of less than once a week, $1-2$ and 3 or more times. Also included was who prescribed the hypnotic, from which medical area the physician was and whether or not the person has used one kind of alternative means to improve sleep.

This research was approved by the Research Ethics Committee from Campinas State University. Informed, free and written consent was signed by all participants.
Descriptive methods were used as well as the tests of chi-square, Fisher exact, and inferences based on parameter of binomial distribution. The significance level adopted was $5 \%$ and the confidence interval $(\mathrm{Cl})$ of $95 \%$.

\section{RESULTS}

The general prevalence of insomnia was $19.1 \%$ ( $\mathrm{sd}=2.0 \% ; \mathrm{Cl}$ from $15.1 \%$ to $23.1 \%$ ) in the city's population, more in women $(25.2 \%$, chi-square $=10.10$, degree of freedom $(D F)=1, p=0.0015)$ and people of less schooling years $(28.6 \%$, chi-square $=10,58, D F=4$, $\mathrm{p}=0.0317$ ) (Tables $1,2,3$ ). The most frequent was DSI (14.2\%, chi-square $=10.89, \mathrm{DF}=2, \mathrm{p}=0.0043) . \mathrm{DSM}$ $(11.1 \%)$ was more frequent in men $(84.6 \%$, chisquare $=10.60, D F=1, p=0.0011)$, ranging from 40 to 59 years old $(81.3 \%, 40-49$ years old and $75.0 \%$ 50-59 years old, chi-square $=10.17, D F=5, p=0.075)$, in lower economic social status $(77.1 \%$, chi-squa$r e=15.56, D F=3, p=0.0014)$; DEA (9.3\%) affected more the martially separated people and widows/widowers $(60 \%$ and $100 \%$, chi-square $=10.1, \mathrm{DF}=3$, $p=0.0185)$. The distribution degree of uneasiness related to DSI, DSM, and DEA was similar (chi-squa$r e=2.58, D F=4 . p=0.6315$ ), as well as the degree of negative effects on activities the following day (chisquare $=0.29, D F=4, p=0.9907$ ).

In the three types of insomnia (DSI, DSM, DEA) the chronic mode was predominant (chi-square $=0.71$, $\mathrm{DF}=2, \mathrm{p}=0.7022$ ) and there were no significant correlation between the degree of negative effects on activities the following day and the social-demographic variables (chi-square $=2.30, D F=2, p=0.3166$ ).

A total of $6.9 \%$ ( $\mathrm{sd}=1.3 \%, \mathrm{Cl}$ between $4.3 \%$ and $8.5 \%$ ) of the subjects used hypnotic drugs in the last month and 68.1 of these were over three times a week (Table 4). It was more frequent in insomniacs (15.4\%, chi-square $=29.8259, \mathrm{DF}=3, \mathrm{p}<0.0001)$, with no prevalence of any sub type (chi-square $=2.95$, $\mathrm{p}=0.2285$ at $\mathrm{DSI}$; chi-square $=1.05, \mathrm{p}=0.5909$ at DSM; and chi-square $=2.90, p=0.2342$ at DEA). In all cases $\mathrm{DF}=2$; not even in the acute or chronic sub types

Table 1. Frequency distribution and relative frequencies of insomnia in relation to the degree of next day impaiment.

\begin{tabular}{|c|c|c|c|c|c|c|}
\hline \multirow[b]{2}{*}{ Daytime impairment } & \multicolumn{2}{|c|}{$\begin{array}{c}\text { Initial } \\
\text { insomnia }\end{array}$} & \multicolumn{2}{|c|}{$\begin{array}{l}\text { Intermediate } \\
\text { insomnia }\end{array}$} & \multicolumn{2}{|c|}{$\begin{array}{l}\text { Terminal } \\
\text { insomnia }\end{array}$} \\
\hline & $\mathrm{N}$ & $(\%)$ & $\mathrm{N}$ & $(\%)$ & $\mathrm{N}$ & (\%) \\
\hline Mild & 15 & 25.90 & 11 & 23.90 & 9 & 23.70 \\
\hline Moderate & 18 & 31.00 & 13 & 28.30 & 11 & 28.90 \\
\hline Severe & 25 & 43.10 & 22 & 47.80 & 18 & 47.40 \\
\hline Total & 58 & 100 & 46 & 100 & 38 & 100 \\
\hline
\end{tabular}


Table 2. Frequency distribution and relative frequencies of acute insomnia in relation to the use of hypnotic drugs.

\begin{tabular}{|c|c|c|c|c|c|c|}
\hline \multirow[b]{2}{*}{ Hypnotic drugs use } & \multicolumn{2}{|c|}{$\begin{array}{c}\text { Initial } \\
\text { insomnia }\end{array}$} & \multicolumn{2}{|c|}{$\begin{array}{l}\text { Intermediate } \\
\text { insomnia }\end{array}$} & \multicolumn{2}{|c|}{$\begin{array}{l}\text { Terminal } \\
\text { insomnia }\end{array}$} \\
\hline & $\mathrm{N}$ & (\%) & $\mathrm{N}$ & (\%) & $\mathrm{N}$ & (\%) \\
\hline Never used & 3 & 100 & & & 1 & 50.0 \\
\hline Use/used & & & 1 & 100 & 1 & 50.0 \\
\hline Total & 3 & 100 & 1 & 100 & 2 & 100 \\
\hline
\end{tabular}

Table 3. Frequency distribution and relative frequencies of chronic insomnia in relation to the use of hypnotic drugs.

\begin{tabular}{|c|c|c|c|c|c|c|}
\hline \multirow[b]{2}{*}{ Hypnotic drugs use } & \multicolumn{2}{|c|}{$\begin{array}{c}\text { Initial } \\
\text { insomnia }\end{array}$} & \multicolumn{2}{|c|}{$\begin{array}{c}\text { Intermediate } \\
\text { insomnia }\end{array}$} & \multicolumn{2}{|c|}{$\begin{array}{l}\text { Terminal } \\
\text { insomnia }\end{array}$} \\
\hline & $\mathrm{N}$ & (\%) & $\mathrm{N}$ & $(\%)$ & $\mathrm{N}$ & (\%) \\
\hline Never used & 30 & 56.6 & 30 & 68.2 & 23 & 63.9 \\
\hline Use/used & 23 & 43.4 & 14 & 31.8 & 13 & 36.1 \\
\hline Total & 53 & 100 & 44 & 100 & 36 & 100 \\
\hline
\end{tabular}

Table 4. Chi-square values applied to the time of use of hypnotic drugs related to sex, age, schooling level, economic social status, marital status, employment, and the presence of insomnia.

\begin{tabular}{lccc}
\hline Variable & Chi-square & $\mathrm{DF}^{*}$ & $\mathrm{p}$ \\
\hline Sex & 26.40 & 4 & $<0.0001$ \\
Age range & 37.89 & 20 & 0.0091 \\
Schooling level & 15.81 & 16 & 0.4663 \\
Economic social & 16.59 & 12 & 0.1657 \\
Marital status & 12.10 & 12 & 0.4374 \\
Employment & 22.70 & 20 & 0.3039 \\
Insomnia & 36.69 & 4 & $<0.0001$ \\
\hline
\end{tabular}

*DF, degree of freedom.

$(p=0.2607$ at DSI $p=0.3333$ at DSM and $p=1.000$ at DEA). The major frequency was in women (chi-squa$\mathrm{re}=8.47, \mathrm{DF}=3, \mathrm{p}=0.0372$ ), and people over 30 years old (chi-square $=24.74, F D=15, p=0.0536$ ). Through their lives they have used hypnotic drugs $17.2 \%$ ( $\mathrm{sd}=1.9 \%, \mathrm{Cl}$ between $13.4 \%$ and $21.0 \%$ ) and $70.3 \%$ of these in the last 2 years, with the same predominance of use in the last month. The other variables did not show any significant association with the time of use of the hypnotic drugs. $91.4 \%$ of the cases of hypnotic use were with a physician's prescription, with no significant predominance of any medical specialty (chi-square $=8.20, \mathrm{DF}=4, \mathrm{p}=0.0844$ ).

There was the use of alternative means to improve sleep in $36.8 \%$ of subjects ( $\mathrm{sd}=2.4$, IC between 32.0 and $41.6 \%$ ), the most frequent being any type of beverage (53.3\%) followed by a shower (31.3\%). Significant association was shown between use of alternative means to improve sleep and presence of insomnia (chi-square $=22.89, D F=1, p=0.0001$ ).

\section{DISCUSSION}

The prevalence of insomnia in general population surveys varies from $12.0 \%$ to $76.3 \%$ depending on the type of criteria used ${ }^{3,5}$. It mostly affects women, divorced people and widow/widowers, unemployed people, elderly people, and those of less schooling years and low economic social status ${ }^{1,5}$. Around 35\% of adult Americans have experienced insomnia in the course of a year. In the same survey, 7.1\% had used hypnotic drugs ( $2.6 \%$ having been used under a physician's prescription and $4.5 \%$ without it) ${ }^{17}$. In a retrospective study in Texas, the authors concluded that there was excessive use of hypnotic sedative agents ${ }^{18}$. The gender variable was evaluated according to longterm use and the dependence on psychotropic drugs, and it was found that men had a higher prevalence with or without a physician's prescription. 
In general, the results obtained with the adult population in Campo Grande, were not very different from other epidemiological national and world studies $3,6,15,18$. In this research, the prevalence of insomnia $19.1 \%$ was similar to other papers $3,4,6,15,19$. The statistically significant associations occurred between insomnia and female sex and insomnia and low educational level. The prevalence of insomnia in general population epidemiological studies with questionnaire filled out in home interviews varied from $10 \%$ to $40 \%{ }^{3,20}$. These studies showed that sleep disorders are more common in elderly people ${ }^{3}$, those with chronic medical diseases, and depressive and anxious disorders ${ }^{21}$. In a French study, the prevalence of $17.7 \%$ insomniacs was detected in the general French population ${ }^{6}$. In a Japanese study with 3600 inhabitants, from 8 urban regions, the prevalence of insomnia was $11.2 \%$; the authors correlated a higher risk of insomnia subjects who lived next to a road of intense traffic ${ }^{22}$. In a large North American epidemiological general population survey $(\mathrm{N}=7954)$ on sleep disorders and psychiatric disturbance, $10.2 \%$ reported insomnia and $40 \%$ of these had a psychiatric disturbance ${ }^{2,23}$. In an epidemiological study in the general population in Switzerland, with a stratified sampling of 600 adults, between 20 and 64 years of age, it was found that $20 \%$ had a disorder of insufficient sleep and $50 \%$ of these had also difficulties in sleeping ${ }^{19}$.

In the general population from Mannheim, Germany, the prevalence of $31 \%$, three times a week for a period of one month ${ }^{24}$ was detected. The sample was sub divided in three groups: short term insomnia (duration shorter than 1 year, $\mathrm{N}=60,19 \%$ ), medium term (duration from 1 to 5 years, $\mathrm{N}=110$, $34 \%$ ), and long-term duration (duration over 5 years, $\mathrm{N}=146,46.2 \%$ ). There were no significant differences in relation to age or $\operatorname{sex}^{24}$. In a study of inland Brazil $^{3}$ with an adult general population survey, an insomnia prevalence $35.4 \%$ was found. About half of the complaints (48\%) of the insomnia had duration up to one year. There was a higher prevalence in women $(47.0 \%)$ than in men $(20.8 \%)$; which increased with age in women (from 35.4\% $18-29$ years old to $60.0 \%$ at 60 years old or over) ${ }^{3}$.

A comprehensive study on the prevalence of insomnia in 12778 French subjects of 18 years old or over was done using a questionnaire sent by mail ${ }^{8}$. The DSM-IV ${ }^{25}$ criteria were used for the definition of insomnia and it had reached a prevalence of $29 \%$ in the frequency of three times a week, in one month, with daytime consequences. Severe insomnia occur- red to $12 \%$ of women and $6.3 \%$ of men. There was no significant increase with age after 35 years old, but there was an increase between 25-34 years of age, independently of sex, while chronic insomnia had a significant increase with age in both sexes. Single people had the least index of insomnia, with being it more frequent in young women ${ }^{8}$.

In an epidemiological home interview based general population survey on the annual prevalence of insomnia in 2418 subjects in Singapore with age between 15 and 60 years an index was detected of $15.3 \%$, comprised of $12.9 \%$ men and $17.5 \%$ women $^{25}$. There was no significant difference between insomniac and non-insomniac groups related to the educational level. However, $26.8 \%$ of married women were insomniacs ${ }^{26}$. An epidemiological study on insomnia was done with the French population using 5622 subjects of 15 years of age or older with telephone interviews. From the sampling, 20.1\% were unsatisfied with their sleep, the majority being women over 65 years old, separated, divorced or widowed and immigrants ${ }^{4}$. There was a wide comparative study of insomnia prevalence in the general population from Portugal and Spain ${ }^{9}$. The study was done with 1858 Portuguese people of 18 years of age or older, and 4065 Spanish people of 15 years of age or older, through a phone survey. Insomnia prevalence was $12.2 \%$ in general population, $15.8 \%$ being in Portugal and $10.6 \%$ in Spain, increasing with age. The prevalence of any diagnosis of insomnia of DSM-IV was greater in Portugal $(8.7 \%)$ than in Spain $(6.0 \%)^{9}$.

In Campo Grande, DSI was the most frequent with a significant association only with female sex. DSM was more frequent in men, and mostly in the age range of 40 and 59 years and in people of low economic social status, especially in the last one. DEA affected mainly separated or widowed people, the single ones being most infrequent. For the degree of subjective uneasiness, there was some similarity in the three sub types DSI, DSM, and DEA. It was different in another city of Brazil with a higher prevalence of intermediary insomnia, followed by initial and terminal insomnia $(27.3 \%, 18.3 \%$, and $14.3 \%$ respectively $)^{3}$. More DSM (10.4\%) was found in Portugal than in Spain $(6.8 \%)^{9}$. Also in a study of the Japanese ${ }^{26}$ population with 3030 interviewed subjects of 20 years old or over, the prevalence of insomnia was $21.4 \%$ being $8.3 \%$ DSI, $15 \%$ DSM, and $8.0 \%$ DEA, mostly aged people, unemployed, with no sport practice, stressed and having little health care. The prevalence of insomnia increased with age, from $18.1 \%$ in young people to $29.5 \%$ in aged peo- 
ple. There was no significant difference between the prevalence of DSI in young people (8.3\%), middleaged people ${ }^{4,10}$, and aged people $(9.7 \%$ ) (chisquare $=4.58, p<0.1)^{26}$. The higher prevalence of insomnia among Japanese women was related to DSI ${ }^{27}$. Other researchers point out more DSM and DEA in the female $\operatorname{sex}^{4,28}$.

There was a predominant evolution to a chronic condition in Campo Grande's population in all types of insomnia - initial, intermediary, and terminal. There was no significant difference in DSI, DSM, and DEA with a degree of negative effects on activities the next day. None of the independent variables showed significant association with this phenomenon.

As to the use of hypnotic drugs, in the month prior to the interview of this study, there was a general prevalence of $6.9 \%, 68.1 \%$ of them being over 3 times a week. They were mostly insomniac women and people over the age of 30 (no significant difference in DSI, DSM, and DEA either chronic or acute). The fewest users were from the highest economic social status, and there was no significant association between the use and educational level, marital status, and occupation. Through the life span there was a prevalence of $17.2 \%$ of use, mostly in the last 2 years $(70.3 \%)$, also more frequent in insomniac, women and people over 30 years old (no differences in DSI, DSM, and DEA either chronic or acute). There was no significant association between the total time of use of hypnotic drugs and other social-demographic variables. In $91.4 \%$ of cases, there was a physician's prescription for the hypnotic drugs, with no significant predominance among the various medical specialties. In a French general population study ${ }^{5}$, $23.9 \%$ severe insomniacs used hypnotic drugs habitually with a physician's prescription. Over half of those used them on a daily basis for 1 to 5 years or more. In Brazil 7 the use of benzodiazepines (BDZ) as daytime sedative or nighttime hypnotic, in 455 adults of 18 years old or more was estimated. The results of the BDZ use in life, for the last year and for the last month were $46.7 \%, 21.2 \%$, and $13.1 \%$ respectively. Among women and widowers or separated people, the prevalence of BDZ use was significantly higher. In Switzerland ${ }^{29}, 7 \%$ of use of hypnotic drugs was found without a medical prescription in groups of chronic insomniac people with ages from 20 to 21 years old and $12 \%$ in the group from 27 to 28 years of age. A Brazilian general population survey ${ }^{3}$ detected $14.6 \%$ of hypnotic drug use in the last month, twice as much as in this paper. In Mexico ${ }^{30}$ it was found that women used more hypnotic drugs than men. In Singapore ${ }^{26}$ it was found that $14 \%$ of the studied sampling used more hypnotic drugs occasionally, and from the users, only $5 \%$ had them on a daily basis. Of the insomniac people in Singapore, $86 \%$ did not use hypnotic drugs; though in this study in Campo Grande, such index being $77.7 \%$. In France ${ }^{4}$, it was found that the use of hypnotic drugs during the life time in the 5622 subjects, of ages of 15 or over, was of $16 \%$, being mostly women over 65 years old, and were immigrants, separated, widowed or divorced.

In Campo Grande, $36.8 \%$ of people sought alternative means to get to improve sleep, almost the same result (31.1\%) as in inland $\mathrm{Brazil}^{3}$. Most users of alternative means were insomniac and $53.3 \%$ used some king of beverage, and $31.3 \%$ used to shower. In the present paper there was no significant correlation between age and the use of alternative means to improve sleep.

In conclusion, a better understanding of Brazilian prevalence of insomnia and hypnotic drugs use may help to identify patients with this important public health problem.

\section{REFERENCES}

1. Walsh J, Ustun B. Prevalence and health consequences of insomnia. Sleep 1999;22(Suppl 3):S427-S36.

2. Ohayon MM. Prevalence of DSM-IV diagnostic criteria of insomnia: distinguishing insomnia related to mental disorders from sleep disorders. J Psychiatr Res 1997;31:333-346.

3. Rocha F. Um estudo com base populacional de hábitos de sono, prevalência e fatores associados a insônia. Tese de Doutorado, Universidade de Brasília. Brasília, 2000.

4. Ohayon M. Epidemiological study on insomnia in the general population. Sleep 1996;19(Suppl 3):S57-S65.

5. Ohayon M, Claudet M, Guilleminault C. How a general population perceives its sleep and how this relates to complaint of insomnia. Sleep 1995;20:715-723.

6. Ohayon M, Claudet M, Lemoine P. Comorbidity of mental and insomnia disorders in thegeneral population. Compr Psychiatr 1998;39:185-197.

7. Wortmann MC, Grudtner M, Fialho AF, et al. Consumo de benzodiazepínicos em Porto Alegre. Rev Assoc Med Bras 1994;40:265-270.

8. Leger D, Guilleminault C, Dreyfus JP, Delahaye C, Paillard M. Prevalence of insomnia in a survey of 12778 adults in France. J Sleep Res 2000;9:35-42.

9. Ohayon M, Paiva T, Segales T. Comparison of insomnia prevalence in the general population of Portugal and Spain. Sleep 2001;24:A345. (Abstract).

10. Reimão R. Padrões e distúrbios do sono em adultos da comunidade negra rural e isoladade Furnas do Dionísio, MS. Tese de Livre-Docência, Faculdade de Medicina da Universidade de São Paulo. São Paulo. 2000.

11. Zammit GK, Weiner J, Damato N, Sillup GP, McMillan CA. Quality of life in people with insomnia. Sleep 1999;22(Suppl 2):S379-S85.

12. Souza JCRP. Quality of life and insomnia in University Psychology students. Human Psychopharmacol 1996;11:169-184.

13. Fundação Instituto Brasileiro de Geografia e Estatística (IBGE). Contagem populacional 1996. Rio de Janeiro: IBGE, 1996.

14. Associação Brasileira dos Institutos de Pesquisa de Mercado (ABIPEME). As características socioeconômicas da população brasileira. São Paulo: ABIPEME, 2000.

15. Giglio SB. Estudo da ocorrência de sonolência excessiva diurna e das relativas àsparassônias na população adulta da cidade de São Paulo. Tese de Doutorado, Escola Paulista de Medicina. São Paulo, 1988.

16. American Sleep Disorders Association. International classification of sleep disorders,revised. Diagnostic and coding manual. Rochester, Minnesota: American Sleep Disorders Association, 1997. 
17. Nishino S, Mignot E. Drug treatment of patients with insomnia and excessive daytime sleepiness: pharmacological considerations. Clin Pharmacokinet 1999;37:305-330.

18. Ohayon M, Caulet M, Priest RG, Guilleminault C. DSM-IV and ICSD-9 insomniasymptoms and sleep dissatisfaction. Br J Psychiatry 1997;171:382-388.

19. Boman JE, Lundh LG, Hetta J. Insufficient sleep in the general population.Neurophysiol Clin 1996;26:30-39.

20. Simon GE, Vonkorff M. Prevalence, burden, and the treatment of insomnia in primarycare. Am J Psychiatry 1997;154:1417-1423.

21. Ulstun T, Privett M, Lecrubier Y. Form, frequency, and burden of sleep problems in general health care. Eur J Psychiatry 1996;11(Suppl 1):S5-S10.

22. Kageyama T, Kabuto M, Kurokawa Y, et al. A population study on risk factors for insomnia among adult Japanese women: a possible effect of road traffic volume. Sleep1997;20:963-971.

23. Buysse DJ, Reynolds CF, Hauri PJ, et al. Diagnostic concordance for DSM-IV sleep disorders: a report from the APA/NIMH DSM-IV field trial. Am J Psychiatry 1994;15:1351-1360.

24. Hohagen F, Kappler C, Schramm E, Riemann D, Weyerer S, Berger M.
Sleep onset insomnia, sleep maintaining insomnia and insomnia with early morning awakening: temporal stability of subtypes in a longitudinal study on general practice attenders. Sleep 1994;17:551-554.

25. American Psychiatric Association. Diagnostic and statistic manual of mental disorders.4.Ed. Washington, D. C.:American Psychiatric Association, 1993.

26. Yeo BKL, Pereira IS, Kok LP, Tsoi WF. Insomnia in the community. Singapore Med J 1996;37:282-284

27. Kim K, Uchiyama M, Okawa M, Liu X, Ogihara K. An epidemiological study of insomnia among the Japanese general population. Sleep 2000;23:41-47.

28. Coren $S$. The prevalence of self-reported sleep disturbance in young adults. Int J Neurosci 1994;79:67-73.

29. Chevalier H, Los F, Boichut D, et al. Evaluation of severe insomnia in the generalpopulation: results of a multinational survey. J Psychopharmacol 1999;13(Suppl 1):S21-S24.

30. Téllez-Lopez A, Sánchez MEG, Torres FG, et al. Hábitos y transtornos del dormir en residentes del área metropolitana de Monterrey. Salud Mental 1995;18:14-22. 